\title{
Analysis of Functional and Radiological Outcome of Total Hip Replacements in Rheumatoid and Osteoarthritis Patients*
}

\author{
Ganesan Ganesan Ram\#, Balasukumar Thamodaran, Thudukuchi Ramanathan Ashok, \\ Suresh Perumal, Vijayaraghavan Phaghal Varthi
}

Department of Orthopaedics, Sri Ramachandra Medical Collage, Chennai, India.

Email: "ganesangram@yahoo.com,dr.balasugumar@gmail.com,drtrashok@gmail.com,drsureshortho@gmail.com

Received September 21 $1^{\text {st }}$, 2013; revised October 21 ${ }^{\text {st }}, 2013$; accepted October $28^{\text {th }}, 2013$

Copyright (c) 2013 Ganesan Ganesan Ram et al. This is an open access article distributed under the Creative Commons Attribution License, which permits unrestricted use, distribution, and reproduction in any medium, provided the original work is properly cited.

\begin{abstract}
Introduction: Outcomes of total hip arthroplasties in rheumatoid are commonly considered as poor and with high rates of complication. Keeping in mind these conflicts of opinions we are going to analyse the functional and radiological outcomes of total hip arthroplasty between osteoarthritis and rheumatoid arthtitis. Patients and Method: Retrospective midterm study of thirty four patients who underwent total hip replacement in Sri Ramachandra medical center for rheumatoid and osteoarthritis (primary and secondary). Of the 44 hips, the indications are rheumatoid arthritis in 20 patients and osteoarthritis in 24 patients. We used the Harris hip score (Modified) for clinical and functional evaluation and plain X-ray pelvis with both hips and proximal femur-AP view and X-ray of the operated hip lateral view for radiological evaluation. Mean follow up is 9 years ( 8 - 13 years). Results: The mean pre and latest harris hip score are 44 and 88 respectively. The mean harris hip score in $1^{\text {st }}, 3^{\text {rd }}$ and $5^{\text {th }}$ years are 86,87 and 87 respectively. The mean pre and latest harris hip score in osteoarthritis is 49 and 92, in rheumatoid arthritis is 35 and 74 . Conclusion: The results in patients who underwent total hip replacement for osteoarthritis are better than those for rheumatoid arthritis, however the gain in harris hip score is the same. As far as complications are concerned there is no difference between rheumatoid and osteoarthritis. Complications are mostly due to the faulty technique. Both uncemented and cemented total hip replacement give good results in non traumatic indications. In bilateral hip diseases there is considerable pain relief and improvement after the first THR, but the optimal improvement is not seen until the second replacement.
\end{abstract}

Keywords: Harris Hip Score; Rheumatoid Arthritis; Osteoarthritis

\section{Introduction}

Osteoarthritis is the most common indication for total hip arthroplasty; it can be primary or secondary to previous trauma or to childhood disorders of the hip. Total hip arthroplasty is often indicated to relieve pain and increase range of motion in patients with rheumatoid arthritis and other collagen diseases. Arthroplasties of the knees and other joints may be necessary. Often these patients are generally disabled, having varying degrees of dermatitis,

*Competing interests: The authors declare that they have no competing interests.

Author's contributions: All authors have contributed to study concept and design, acquisition of data, and critical revision of the manuscript. All authors have read and approved the final manuscript.

${ }^{\#}$ Corresponding author. vasculitis, fragile skin, osteopenia, and poor musculature. In addition, they have been or are receiving steroids and other immunosuppressive drugs; consequently, the risks of fracture during surgery and infection after surgery are greater. The femoral head may be partially absent because of erosion or osteonecrosis, and the femoral head may have protruded into the pelvis. Always results in rheumatoid are considered poor and complication rates are high. Keeping in mind these conflicts of opinions we are going to analyse the midterm functional and radiological outcomes of total hip arthroplasty between osteoarthritis and rheumatoid arthritis patients.

\section{Patients and Method}

Retrospective study of thirty four patients who under- 
went total hip replacement in Sri Ramachandra medical center for rheumatoid and osteoarthritis (primary and secondary). The study period was from March 2010 to Dec. 2012. The youngest patient was 23 yrs and the oldest was 75 yrs. 24 patients underwent unilateral total hip replacement while 10 underwent bilateral total hip replacement. Out of the 44 hips, 20 hips were cemented and 24 hips were uncemented. The uncemented hip replacement was done in males below 60 yrs and females below 55 yrs of age [1,2]. However, the cemented hip replacement was used in patients for whom economy was a constraint. The follow-up was from 8 years to 13 years. The indications were rheumatoid arthritis (20) and osteoarthritis (24). The posterior approach was used in 24 cases and the lateral approach in 20 cases. The approach was selected randomly by choice of the surgeon for both unilateral and bilateral patients. Informed consent was obtained from patients after discussion of the advantages and risk of each approach.

We used the Harris hip score [3] (Modified) for clinical and functional evaluation and plain X-ray pelvis with both hips and proximal femur-AP view and X-ray of the operated hip-lateral view for radiological evaluation. All the patients were followed up regularly at immediate postop, 6 weeks, 3 months, 6 months and then yearly upto 8 - 13 yrs. The Andrew Whaley and Daniel et al. criteria [4] for uncemented cups and the De Lee and Charnley criteria for cemented cups were used to assess cup loosening. The Gruen zones [5] for cemented stems and the Enghs criteria for uncemented stems were used to assess femoral stem loosening. Other radiological components that were taken into consideration were cup inclination, femoral stem position, vertical subsidence of femoral component, vertical migration of acetabular component and heterotrophic ossification. The Brookers Classification [6] was used to assess Heterotropic Ossification.

\section{Results}

The mean preoperative and latest harris hip score were 44 and 88 respectively. The mean harris hip score at the end of $1^{\text {st }}, 3^{\text {rd }}$ and $5^{\text {th }}$ years follow up were 86,87 and 87 respectively.

\section{Complications}

In our series we had a dislocation rate of 2.3\% (1 hip) $2.3 \%$ incidence of aseptic acetabular loosening (1 hip) $13.6 \%$ incidence of anterior thigh pain (6 pts) and a $11.3 \%$ incidence of heterotrophic ossification (5 hips). Five pts (11.3\%) had a limb length discrepancy of $1-1.5$ cms. We had no infection in our series.

\section{Discussion}

The mean pre op and latest harris hip score in our study were 44 and 88 . This was comparable to the study by Wixson et al. [7] whose mean pre and post op harris hip score was 44 and 93 respectively and Siwach et al. [8] whose mean pre and post op harris hip score were 44 and 83.5. Mean pre op and latest harris hip score in cemented hips was 40 and 85 which was comparable to that of Wixson et al. 42 and 90. Mean pre and post op harris hip score in uncemented hips was 48 and 89 which was comparable to that of Wixson et al. who had 47 and 95.

Our mean $1^{\text {st }}, 3^{\text {rd }}, 5^{\text {th }}$ yr harris hip scores of $86,87 \&$ 87 were comparable to that of C.Y.NG et al. [9] and Goran et al. [10] who both had 88, 89 \& 89 respectively. The greatest change occurred between pre op assessment and review at 6 months. The patients had the potential to improve further until 18 months. Further the scores plateaued. Our series had a ceiling effect [11] of $15 \%$ which was considered as the acceptable limit in literatures.

From Table 1 our study of unilateral versus bilateral total hip replacement was comparable with the study of Anders Wykman et al. [4]. Although patients with bilateral disease gain considerable pain relief and improvement after the first total hip replacement, the optimal improvement is not seen until after the second replacement.

On analysing the difference in pre operative and latest Harris hip score for rheumatoid and osteoarthritis from Table 2 our study showed no significant difference in gain of harris hip score in Osteoarthritis and Rheumatoid arthritis. Our series of patient with Osteoarthritis have pre and latest harris hip score as 49 and 92. The Harris hip score in Rheumatoid arthritis patients in our series was 35 and 74 which is comparable with Johnson et al.'s [12] scores of 41 and 78.

In our series we had two patients (4.5\%) for whom bilateral total hip replacement and total knee replacement

Table 1. Unilateral versus bilateral HHS.

\begin{tabular}{ccc}
\hline & Pre op HHS & Latest HHS \\
\hline Unilateral & 48 & 88 \\
Bilateral & & \\
After one hip & 40 & 65 \\
After both hip & 40 & 87 \\
\hline
\end{tabular}

Table 2. Mean Harris hip score.

\begin{tabular}{cccc}
\hline Condition & Pre OP & Latest & Difference in HHS \\
\hline OA & 49 & 92 & 43 \\
RA & 35 & 74 & 39 \\
\hline
\end{tabular}


was done for rheumatoid arthritis. Their mean Harris hip score of 20 and 68 were comparable with the results of Kenneth et al. [12] score of 25 and 75. The preferred method of arthroplasty in these cases was to operate on the hips before the knees, and on the more diseased of each pair of joint. The relief of pain was the single factor that accounted for the increase in hip rating.

In our series we had $86 \%$ excellent/good results and 14\% poor/fair (Table 3) results which can be compared with Wixson et al. who has $89 \%$ excellent/good and $11 \%$ poor/fair results. In our series the poor results (6 hips) came in cases of rheumatoid arthritis however the gain in harris hip score was same as in osteoarthritis. All these patients had involvement of other joints and two patients had bilateral total hip replacement and total knee replacement done.

\section{Radiological Outcome}

We had 1 case (2.6\%) of acetabular loosening (aseptic loosening). The loosening occurred in the case of uncemented acetabular component (Figure 1). The patient was a case of rheumatoid arthritis operated through posterior approach with a St. Nabor cup and Wagner stem. Hip showed radiographic evidence of loosening 8 years following the primary surgery. Since patient did not have any symptoms of cup loosening, revision of the cup was not advised to the patient. 12 years following the primary surgery, patient presented with symptomatic loosening of the acetabular component (St. Nabor Cup). Acetabular cup revision (Figure 2) was done retaining the intact femoral component (Wagner stem). The mean interval between primary surgery and diagnosis of loosening was 7.8 years in the study by Engh C.A et al. which corresponded to interval of 8 years in our study [13].

The age of the patient at time of primary total hip arthroplasty was 43 years. This corresponded to the results of Engh C.A which revealed higher incidence of osteolysis and reoperation in young patients. In the study by John C and W.H. Harris [14], 4\% of the acetabular components were revised. In our study $2.6 \%$, i.e. 1 acetabular component was revised. The pattern of osteolysis in our case was localized and expansile. This pattern corresponded to the pattern of osteolysis in the study by B.

Table 3. Results of harris hip score.

\begin{tabular}{ccc}
\hline Result & Number & Percentage \\
\hline Excellent & 26 & $59 \%$ \\
Good & 12 & $27 \%$ \\
Fair & 0 & $0 \%$ \\
Poor & 6 & $14 \%$ \\
\hline
\end{tabular}

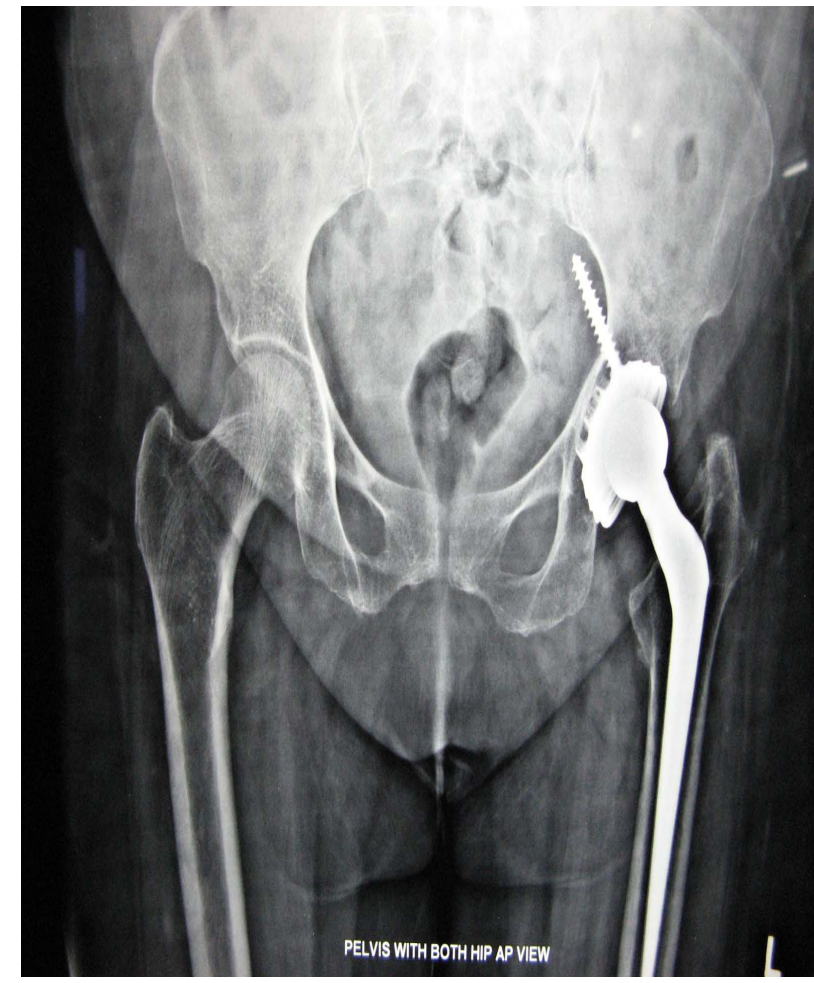

Figure 1. Loosening of cup.

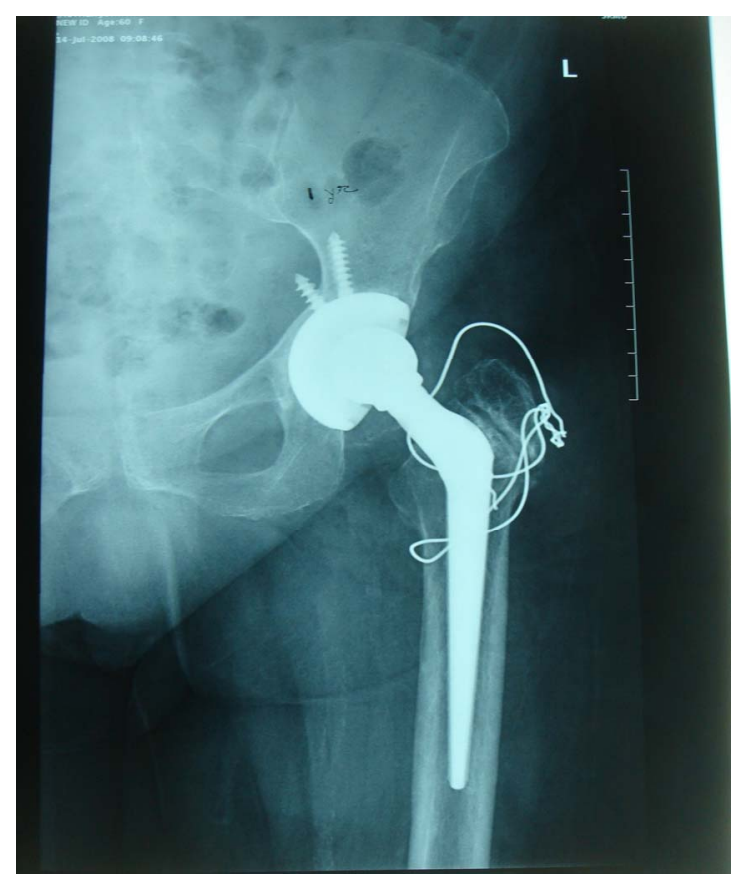

Figure 2. Revision of cup.

Zicat and Engh C.A. However, long term follow-up was necessary in order to evaluate the potential mechanisms of failure of the acetabular component, including excessive polyethylene wear, dysfunction of the locking mechanism, dissociation of the liner and pelvic osteolysis. 
We had 21 cups in neutral position, 15 vertical and 2 horizontal. One of the vertical cups had aseptic loosening and one vertical cup had dislocation. (M.A.Ali khan et al. [15]). The ideal femoral stem position was central. In our study we had 26 stems in central, 9 in valgus, 3 in varus. As of now we did not had any complications. We had no subsidence or migration.

In our series we had 1 case of dislocation (2.6\%) in a osteoarthritic patient (Figure 3). The dislocation occurred during the first month of the surgery at home. For this patient the cup was placed vertically and posterior approach was used. Dislocation was openly reduced and trochantric osteotomy was done for that patient (Figure 4). The study of Wayne M. Goldstein et al. [16] shows an increased rate of dislocation following posterior approach. His study shows dislocation rate of $2.8 \%$ following posterior approach which was correlating with our study. Charlotte B. Philips et al. [17] study shows a dislocation rate of $3.9 \%$. The incidence of dislocation was highest during the immediate post operative period but remain elevated throughout the first three post operative months.

Heterotopic ossification was a relatively common complication after total hip arthroplasty. It usually first becomes visible on radiographs three to four weeks after surgery and matures by three to six months [18]. The incidence ranges from $5 \%$ to $90 \%$ in various literatures [19]. In our series we have 5 cases (11.3\%) of class 2 heterotrophic ossification. All the cases are uncemented. 3 cases had diagnosis of osteoarthritis and 2 had rheu-

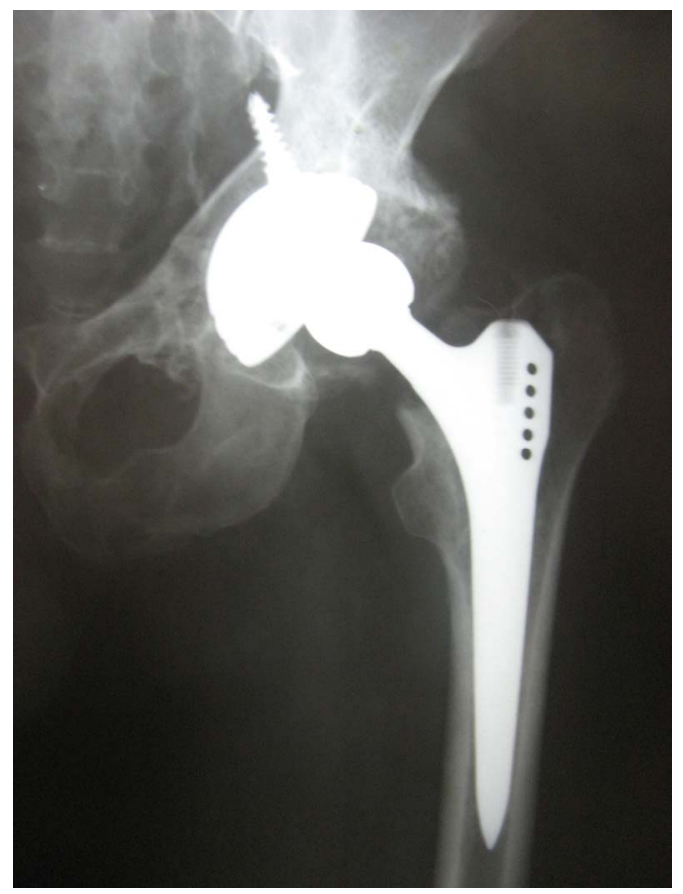

Figure 3. Subluxation.

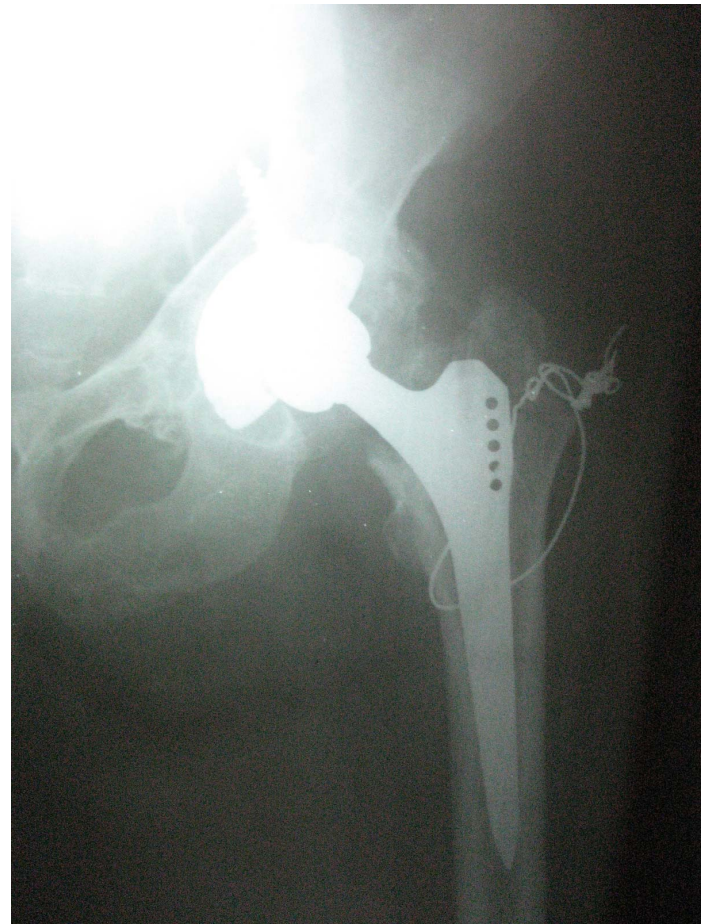

Figure 4. Post op reduction.

matoid arthritis. The particulate bone debris and the escape of femoral bone marrow elements, which were normally sealed off by bone cement in a cemented femoral component may be increased when an uncemented implant was used.

\section{Conclusion}

The Harris hip score is a useful scoring system in assessing total hip replacement done for non traumatic indications and showed high validity and reliability. We have $86 \%$ excellent/good results in our series. The results in patients osteoarthritis were better than those with rheumatoid arthritis, however the gain in harris hip score is the same. As far as complications are concerned there is no difference between rheumatoid and osteoarthritis. Complications are mostly due to the faulty technique. Both Uncemented and cemented total hip replacement give good results in non traumatic indications. In bilateral hip diseases there is considerable pain relief and improvement after the first THR, but the optimal improvement is not seen until the second replacement.

\section{REFERENCES}

[1] K. T. Mäkelä, A. Eskelinen, P. Pulkkinen, P. Virolainen, P. Paavolainen and V. Remes, "Cemented versus Cementless Total Hip Replacements in Patients Fifty-Five Years of Age or Older with Rheumatoid Arthritis,” The Journal of Bone \& Joint Surgery, Vol. 93, No. 2, 2011, pp. 178- 
186. http://dx.doi.org/10.2106/JBJS.I.01283

[2] K. T. Mäkelä, A. Eskelinen, P. Pulkkinen, P. Paavolainen and V. Remes, "Total Hip Arthroplasty for Primary Osteoarthritis in Patients Fifty-Five Years of Age or Older. An Analysis of the Finnish Arthroplasty Registry," The Journal of Bone \& Joint Surgery, Vol. 90, No. 10, 2008, pp. 2160-2170.

[3] W. H. Harris, "Traumatic Arthritis of the Hip after Dislocation and Acetabular Fractures: Treatment by Mold Arthroplasty. An End-Result Study Using a New Method of Result Evaluation,” The Journal of Bone \& Joint Surgery, Vol. 51, No. 4, 1969, pp. 737-755.

[4] A. Wykman and E. Olsson, "Walking Ability after thr. A Comparison of Gait Analysisin Unilateral and Bilateralcases,” The Journal of Bone \& Joint Surgery, Vol. 74, No. 1, 1992, pp. 53-56.

[5] J. W. Harkess and J. R. Crocaralle, "Arthroplasty of the Hip,” In: T. Canale, Ed., Campbell's Operative Orthopaedics, International Edition, Elsevier Tenth Edition, Mosby, pp. 180-290.

[6] A. F. Brooker, J. W. Bowerman, R. A. Robinson and L. H. Riley Jr., "Ectopicossification Following Total Hip Replacement. Incidence and a Method of Classification," The Journal of Bone \& Joint Surgery, Vol. 55, No. 8, 1973, pp. 1629-1632.

[7] R. L. Wixson, S. D. Stulberg and M. Mehlhoff, "Total Hip Replacement with Cemented, Uncemented, and Hybrid Prostheses. A Comparison of Clinical and Radiographic Results at Two to Four Years," The Journal of Bone \& Joint Surgery, Vol. 73, No. 2, 1991, pp. 257-270.

[8] R. Siwach, V. S. Kadyan, S. Sangwan and R. Gupta, “A Retrospective Study of Total Hip Arthroplasty,” Indian Journal of Orthopaedics, Vol. 41, No. 1, 2007, pp. 62-66.

[9] C. Y. Ng, J. A. Ballantyne and I. J. Brenkel, “Quality of Life and Functional Outcome after Primary Total Hip Replacement. A Five-Year Follow-Up," The Journal of Bone \& Joint Surgery, Vol. 89, No. 7, 2007, pp. 868-873.

[10] G. Malchau and H. Herberts, "Specific or General Health Outcome Measures in the Evaluation of Total Hip Replacement. A comparison between the Harris Hip Score and Health Profile,” The Journal of Bone \& Joint Surgery,
Vol. 80, No. 4, 1998, pp. 600-606.

[11] K. E. Wamper, I. N. Sierevelt, R. W. Poolman, M. Bhandari and D. Haverkamp, "The Harris Hip Score: Do Ceiling Effects Limit Its Usefulness?” Acta Orthopaedica, Vol. 81, No. 60, 2010, p. 703.

[12] K. A. Johnson, “Arthroplasty of Both Hips and Both Knees in Rheumatoid Arthritis," The Journal of Bone \& Joint Surgery, Vol. 57, No. 7, 1975, pp. 901-904.

[13] B. Zicat, C. A. Engh and E. Gokcen, "Patterns of Osteolysis around Total Hip Components Inserted with and without Cement,” The Journal of Bone \& Joint Surgery, Vol. 77, No. 3, 1995, pp. 432-434.

[14] J. C. Clohisy and W. H. Harris, "The Harris-Galante Porous-Coated Acetabular Component with Screw Fixation. An Average Ten-Year Follow-Up Study,” The Journal of Bone \& Joint Surgery, Vol. 81, No. 1, 1999, pp. 66-73.

[15] M. A. Ali Khan and P. H. Brakenbury, "Reynolds IS Dislocation Following Total Hip Replacement,” The Journal of Bone \& Joint Surgery, Vol. 63-B, No. 2, 1981, pp. 214-218.

[16] W. M. Goldstein, T. F. Gleason, M. Kopplin and J. J. Branson Prevalence of Dislocation after Total Hip Arthroplasty through a Posterolateral Approach with Partial Capsulotomy and Capsulorrhaphy," The Journal of Bone \& Joint Surgery, Vol. 83-A, No. S2, 2001, pp. 2-7.

[17] C. B. Phillips, J. A. Barrett, E. Losina, N. N. Mahomed, E. A. Lingard, E. Guadagnoli, J. A. Baron, W. H. Harris, R. Poss and J. N. Katz, "Incidence Rates of Dislocation, Pulmonary Embolism, and Deep Infection during the First Six Months after Elective Total Hip Replacement," The Journal of Bone \& Joint Surgery, Vol. 85-A, No. 1, 2003, pp. 20-26.

[18] D. Jesse, F. Antonio and C. John, "Ectopic Bone Formation Following Low Friction Arthroplasty of the Hip," Clinical Orthopaedics, Vol. 121, 1976, pp. 53-57.

[19] S. Rosendahl, J. K. Christoffersen and M. Norgaard, "Para-articular Ossification Following Hip Replacement. 70 Arthroplasties ad Modum Moore Using McFarland's Approach," Acta Orthopaedica, Vol. 48, No. 4, 1977, pp. 400-404. http://dx.doi.org/10.3109/17453677708992016

\section{List of Abbreviations}

OA-Osteoarthritis

RA-Rheumatoid arthritis

HHS-Harris Hip Score 